\section{Biochemical and histopatholog- ical changes in the kidney and adrenal gland of rats following repeated exposure to lambda-cyhalothrin}

\author{
Hassina Khaldoun Oularbi \\ Research Laboratory of Animal Biology \\ and Physiology, E.N.S, Kouba, Algiers; \\ Department of Biology, Faculty \\ of Agro-Veterinary Sciences, University \\ Blida 1, Algeria
}

\section{Abstract}

Lambda-cyhalothrin (LCT) is a type II pyrethroid insecticide widely used in pest management. This study was undertaken to evaluate the toxic effects of LCT on the kidneys and adrenal glands of rats after subacute exposure. Twenty-eight 6-week-old male albino Rattus norvegicus rats were randomly assigned to four groups. Group 1 was the control group, which received distilled water. The experimental groups 2, 3 and 4 received 20.4, 30.6 and $61.2 \mathrm{mg} / \mathrm{kg}$ body weight, respectively, of LCT, administered orally over 28 days. The effects of the insecticide on various biochemical parameters were evaluated at 14 and 28 days. Histopathological studies were carried out in the kidneys and adrenal glands at the end of the experiment. Lambda-cyhalothrin, as a pyrethroid insecticide, induced significant increases $(\mathrm{P} \leq 0.05)$ in plasma urea, creatinine, uric acid and glucose concentrations, and alanine aminotransferase and aspartate aminotransferase activities after 14 and 28 days. In the rat plasma samples after 28 days, residual concentrations of LCT 1R, cis, S cyhalothrin (1) and 1S, cis, R, cyhalothrin (2) were clearly detected. All experimental animals showed dose-dependent organ pathologies, such as necrotic degeneration of the adrenal glands and narrowed appearance of Bowman's space, degeneration of tubular epithelial lining, widened lumen, and tissue congestion in the kidney. It can be concluded that lambda cyhalothrin is highly toxic for rat adrenal glands and kidneys.

\section{Introduction}

It is well known that pesticide usage is beneficial for increasing agricultural productivity and reducing insect-borne diseases. The principal classes of pesticides in current use are organochlorines, organophosphates, carbamates and pyrethroids. Unfortunately, these toxic chemicals have detrimental impacts on the environment, affect biological systems and are harmful to human health. ${ }^{1,2}$ Pyrethroids are synthetic analogues of pyrethrins I, naturally occurring insecticides extracted from the dried flowers of Chrysanthemum cinerariaefolium..$^{3,4}$ Synthetic pyrethroids are used in agriculture, forestry, horticulture and public health;, ${ }^{4,5}$ they are a unique group of insecticides that comprise over $30 \%$ of all insecticides used globally. ${ }^{6}$ Their action on voltage sensitive sodium channels, voltage sensitive calcium channels, voltage sensitive chloride channels, $\mathrm{GABA}_{\mathrm{A}}$ receptors and modulation in the release of neurotransmitters especially acetylcholine, dopamine and serotonin have been suggested in their neurotoxicity.,7-11 These persistent organic pollutants are categorized as type I and type II pyrethroids, which differ in chemical structure and mechanisms of action, type II pyrethroids being more toxic than type I. ${ }^{12-}$ ${ }^{14}$ Synthetic pyrethroids can have one, two or three chiral centers so they present two, four or eight stereoisomers respectively. Lambdacyhalothrin (LCT), a type II pyrethroid $\left(\mathrm{C}_{22} \mathrm{H}_{19} \mathrm{CIF}_{3} \mathrm{NO}_{3}\right)$, is a halogenated pyrethroid composed of a 1:1 mixture of two stereoisomers, namely [(S)-a-cyano-3-phenoxy benzyl(Z)-(1R,3R)-3-(2-chloro-3,3,3-trifluoroprop-1enyl)-2,2-dimethyl cyclo propane carboxylate and (R)-a-cyano-3 phenoxy-benzyl-(Z)-(1S, $3 \mathrm{~S})$-3-(2-chloro-3,3,3-trifluoroprop-1-enyl)2,2-dimethyl cyclo propane carboxylate $]^{12,15}$ (Figure 1). Alpha-cyano pyrethroid affects chloride and calcium channels, which are important for normal nerve function. ${ }^{8}$ LCT induces anxiety-like symptoms in rats and inhibits the activity of acetylcholinesterase in Channa punctatus (Bloch). ${ }^{16}$ The residue analysis of pyrethroids is of importance in environmental science. Conventional pesticide residue analyses of pyrethroids mostly focus on chromatographic separation using high performance liquid chromatography, gas chromatography (GC), or coupled column liquid chromatography/mass spectrophotometry. ${ }^{12,13,17}$ The FAO/WHO ${ }^{18}$ suggested a GCMS method for the analysis of the active ingredient of lambda cyhalothrin, using external standard calibration. LCT has been found to have adverse effects on many tissues: it induces stress-like symptoms and oxidative damage in mammalian tissues such as the liver, kidneys and reproductive organs. ${ }^{5,19,20}$ Histological changes provide a rapid means for detecting the effects of this pesticide in various animal tissues and organs, such as the kidneys and the adrenal glands, which perform very important physiological functions related to electrolyte homeostasis and many other aspects of normal metabolism. ${ }^{21,22}$ This study therefore aims to provide the first detailed description of
Correspondence: Hassina Khaldoun Oularbi, Department of Biology, Faculty of Agro-Veterinary Sciences, University Blida 1, Algeria.

E-mail: hkhaldoun2005@yahoo.fr

Key words: lambda-cyhalothrin, biochemical, histopathology, adrenal gland, kidney.

Acknowledgements: the author thanks F. Benddine of the Algerian Ministry of Agriculture and Rural Development (Direction de la Protection des Végétaux et des Contrôles Techniques, DPVCT) for providing the lambdacyhalothrin standard. I also thank Professor A. Baz of the Animal Biology and Physiology Research Laboratory (E.N.S, Kouba, Algiers, Algeria) and Professor M. Lhermitte and D. Patrick (Laboratoire de Toxicologie, CHRU de Lille, France) for plasma lambda-cyhalothrin concentration determination and technical assistance in the setting up of GC-MS/MS conditions.

Conflict of interests: the author declares no potential conflict of interests.

Received for publication: 16 January 2014.

Revision received: 5 March 2014

Accepted for publication: 10 March 2014.

This work is licensed under a Creative Commons Attribution NonCommercial 3.0 License (CC BYNC 3.0).

(C)Copyright H. Khaldoun Oularbi, 2014

Licensee PAGEPress, Italy

Journal of Xenobiotics 2014: 4.2240

doi:10.4081/xeno.2014.2240

pathology in the kidney and adrenal glands during subacute LCT exposure and to further investigate the dose effect of lambdacyhalothrin (LTC) on biochemical parameters. It also assesses the application of a GCMS/MS method for LCT residual measurement in plasma.

\section{Materials and Methods}

\section{Chemicals}

A pure reference standard of lambdacyhalothrin $\left(\mathrm{C}_{23} \mathrm{H}_{19} \mathrm{CIF}_{3} \mathrm{NO}_{3}\right)$, ( $>98.9 \%$, purity, Syngenta Corp., Greensboro, NC, USA) was purchased from the Ministry of Agriculture and Rural Development (Direction de la Protection des Végétaux et des Contrôles Techniques, DPVCT) of Algeria. A commercial formulation of LCT named Karate $Z^{\mathrm{TM}}$ ( $\lambda$-cyhalothrin 50 $\mathrm{g} / \mathrm{L}$; Syngenta Corp.) was used in the experiments. All other reagents used were obtained from commercial sources: Biosolve Chimie (Valkenswaard, Netherlands) and BIOLABO SA (Maizy, France). 


\section{Animals and treatment}

Twenty-eight 6-week-old male albino Rattus norvegicus rats weighing $160 \pm 10 \mathrm{~g}$ were obtained from CRD-SAIDAL (El Harrach, Algeria) and kept under conditions of $12 \mathrm{~h}$ light/dark cycle and controlled temperature $\left(22 \pm 3^{\circ} \mathrm{C}\right)$. They were accustomed to laboratory conditions for 8 days. All animals had free access to a commercial standard pellet diet (ONAB: Office National des Aliments de Bétail, Algiers) and water ad libitum. All animals were treated according to the standard procedures laid down by OECD guideline 407 for repeateddose 28-day oral toxicity studies in rodents. ${ }^{23}$ The rats were randomly assigned to 4 groups of 7 animals each. Group 1 was the control group, which received distilled water, while the experimental groups 2, 3, and 4 received an aqueous solution of LCT at three different doses: 20.4 $\mathrm{mg} / \mathrm{kg}$ b.w., $30.6 \mathrm{mg} / \mathrm{kg}$ b.w. and $61.2 \mathrm{mg} / \mathrm{kg}$ b.w., respectively, daily for 28 days by gavage. The toxic doses represented 1/30, 1/20 and $1 / 10$, respectively, of LCT $\mathrm{LD}_{50}$ and were calculated according to the animal's body weight on the day before dosing. The $\mathrm{LD}_{50}$ in our study was $612 \mathrm{mg} / \mathrm{kg}$ body weight, which has been used previously by other authors. ${ }^{24-26}$ The animals were weighed every day throughout the acclimation and experimentation periods. At the end of the experiments, the rats were euth-

(S)-alcohol (Z)-(1R)-cis-acid<smiles>CC1[C@H](C=C(Cl)C(F)(F)F)[C@H]1C(=O)O[C@@H](C#N)c1cccc(Oc2ccccc2)c1</smiles>

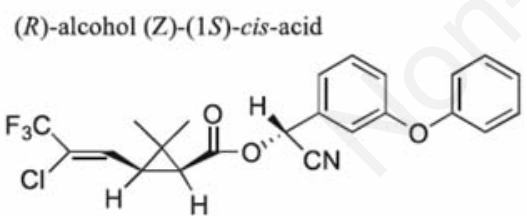

Figure 1. Chemical structure of lambdacyhalothrin. anized by cervical decapitation under light diethyl ether anesthesia.

\section{Biochemical analysis}

This study involved two exposure periods of 14 days each. After 14 and 28 days of administration of LCT, blood samples were collected from the retro-orbital sinus for biochemical evaluation. Plasma samples for biochemical parameters were obtained by centrifugation of blood at 3000 revolutions per minute for 20 min. Levels of plasma creatinine, blood urea, uric acid, glucose, alanine aminotransferase (ALAT) and aspartate aminotransferase (ASAT) were measured by spectrophotometry (Shimadzu, UV-1700) using commercial assay kits (BIOLABO SA) according to the manufacturer's directions.

\section{Plasma lambda-cyhalothrin concentration}

The analysis of rat plasma for lambda cyhalothrin was performed in a GC-MS/MS system, coupled with a tandem mass spectrometer (Quattro Micro TM GC MICROMASS®; Waters Corp., Milford, MA, USA). Chromatographic separation was achieved with a fused silica capillary column AT5-ms (ref: 15807; Alltech, Templemars, France) (30 $\mathrm{m} \times 0.25 \mathrm{~mm} \times 0.25$ $\mathrm{m})$. One $\mu \mathrm{L}$ was injected in splitless mode at an injection temperature of $250^{\circ} \mathrm{C}$. The initial oven temperature of $25^{\circ} \mathrm{C}$ was kept for $2 \mathrm{~min}$, increased to $250^{\circ} \mathrm{C}$, and then kept at this temperature for $8 \mathrm{~min}$. Retention times were 8 min for the standard used for LCT quantification (PCB -166), and $12.40 \mathrm{~min}$ and $12.85 \mathrm{~min}$ for cyhalothrin 1 and cyhalothrin 2 respectively. All data collected were acquired using Mass Lynx ${ }^{\mathrm{TM}}$ NT 4.1 software.

\section{Histopathological examination}

After euthanasia, the kidneys and adrenal glands were isolated and fixed in $10 \%$ buffered formalin. Each was processed in an automatic tissue processor and embedded in paraffin. Thin sections of 2-3 $\mu \mathrm{m}$ were cut, and stained with hematoxylin and eosin for pathological evaluation under the microscope.

\section{Statistical analysis}

Data were analyzed using Statistica, version 10.0 (StatSoft Inc., Tulsa,OK, USA). The results are presented as mean \pm SD. Statistical significance between the control and treated groups was determined by one-way analysis of variance (ANOVA) followed by a Newman-Keuls test. Values of $\mathrm{P}<0.05$ were regarded as statistically significant.

\section{Results}

\section{Body weight}

There were no statistically significant differences $(\mathrm{P}<0.05)$ between groups 1, 2, 3 and 4 during the acclimatization period. During the experimental period, there was no statistical difference between group 2 and the control group 1, while LCT at 30.6 and $61.2 \mathrm{mg} / \mathrm{kg}$ body weight (groups 3 and 4 respectively) decreased the body weight and average feed intake significantly $(\mathrm{P}<0.05)$ compared to the other groups. Similarly, a significant decrease was observed in the absolute weight of the kidney at low and middle doses, with an increase in the kidney's relative weight at high dose. In contrast, the results indicate that treatment with LCT did not affect the absolute and relative weights of adrenal glands. The results of the effects of different doses of LCT on body and organ weights and average feed intake are summarized in Figure 2, Table 1.

\section{Biochemical results}

The effects of LCT on biochemical parameters in the rats are given in Table 2. LCT exposure caused a significant increase $(\mathrm{P}<0.05)$ in plasma levels of glucose, creatinine, urea, uric acid and ASAT and ALAT activities in rats treated with 30.6 and $61.2 \mathrm{mg} / \mathrm{kg}$ LCT at 14 and 28 days of treatment compared with those of the control group.

\section{Plasma lambda-cyhalothrin \\ concentration}

Lambda cyhalothrin was found in the plasma samples analyzed but in very low concentrations below the quantification limit $(1 \mathrm{ng} / \mathrm{g})$ after 14 days of treatment. However, on day 28 residual concentrations of the two isomers of LCT (1R, cis, S and 1S, cis, R) were found in all plasma of rats treated with $30.6 \mathrm{mg} / \mathrm{kg}$

Table 1. Effect of three doses of lambda-cyhalothrin $(20.4,30.6$ and $61.2 \mathrm{mg} / \mathrm{kg} \mathrm{b.w.)}$ on initial and final body weights, average feed intake, and kidney and adrenal-gland weights.

\begin{tabular}{lccccccc} 
Groups & \multicolumn{3}{c}{$\begin{array}{c}\text { Body weight }(\mathrm{g}) \\
\text { Final }\end{array}$} & $\begin{array}{c}\text { Avsolute weight }(\mathrm{g}) \\
\text { Average feed intake }\end{array}$ & \multicolumn{2}{c}{$\begin{array}{c}\text { Relative weight }(\mathrm{g}) \\
\text { Adrenals }\end{array}$} & $\begin{array}{c}\text { Kidney } \\
\text { Adrenals }\end{array}$ \\
Control & $167 \pm 10$ & $232 \pm 13$ & $20.45 \pm 0.38$ & $1.72 \pm 6$ & $0.031 \pm 4$ & $0.74 \pm 0.3$ & $0.013 \pm 0.6$ \\
Low LCT & $163 \pm 8$ & $230 \pm 16$ & $19.21 \pm 0.65$ & $1.64 \pm 3^{*}$ & $0.032 \pm 2$ & $0.71 \pm 0.8$ & $0.013 \pm 0.4$ \\
\hline Mid LCT & $162 \pm 8$ & $226 \pm 16^{*}$ & $16.51 \pm 25^{*}$ & $1.80 \pm 2^{*}$ & $0.031 \pm 5$ & $0.79 \pm 0.5$ & $0.013 \pm 0.2$ \\
High LCT & $165 \pm 10$ & $198 \pm 9^{*}$ & $13.11 \pm 32^{*}$ & $1.78 \pm 5$ & $0.030 \pm 3$ & $0.89 \pm 0.1^{*}$ & $0.015 \pm 0.5$ \\
\hline
\end{tabular}

LCT, lambda-cyhalothrin. Values are mean $\pm \mathrm{SD}(\mathrm{n}=7$ for each group). *Significant $(\mathrm{P}<0.05)$ effects of different treatments. 
[7.21 \pm 2.45 and $4.96 \pm 4.09 \mathrm{ng} / \mathrm{mL}]$ and 61.2 $\mathrm{mg} / \mathrm{kg}[24.87 \pm 4.51$ and $31.08 \pm 2.43 \mathrm{ng} / \mathrm{mL}]$ of LCT. Mean LCT concentrations in the rat plasmas are compared in Figure 3.

\section{Histological results}

\section{Kidney}

Histological examination of the kidney sections (Figure 4) of the control group revealed normal cortex with normal renal corpuscles and normal proximal and distal tubules. Animals treated with the low dose of LCT also showed normal renal cortex. In the LTC middle dose group, the renal cortex showed massive congestion. There were dose-dependent changes in the cortex and medulla, the changes being more marked in group 4 . The main findings were: a narrowed appearance of Bowman's space, degeneration of tubular epithelial lining, widened lumen and tissue congestion.

\section{Adrenal gland}

Histological examination of the adrenal gland sections (Figure 5) of the control group revealed normal cortex, with zona reticularis, zona fasciculata and zona glomerulosa. LCT induced histopathological alterations in the adrenal glands and these changes increased in a dose dependant manner. Animals treated with low, middle and high doses of LCT showed necrosis in the cortex, massive congestion and hemorrhage.

\section{Discussion}

Humans are exposed to a mixture of environmental pollutants, such as pesticides, by various routes of exposure: air, food and water. These compounds have the potential to disrupt endocrine processes, resulting in reproductive problems, cancers and other effects. ${ }^{27}$ Lambda cyhalothrin is a synthetic pyrethroid insecticide, widely used in pesticides, which affects different organs. ${ }^{5,9}$ In this study, biochemical and histological changes in the kidney and adrenal gland were examined in rats after subacute exposure to high doses of LCT. Based on the results of the present study, potential systemic effects of LCT administered

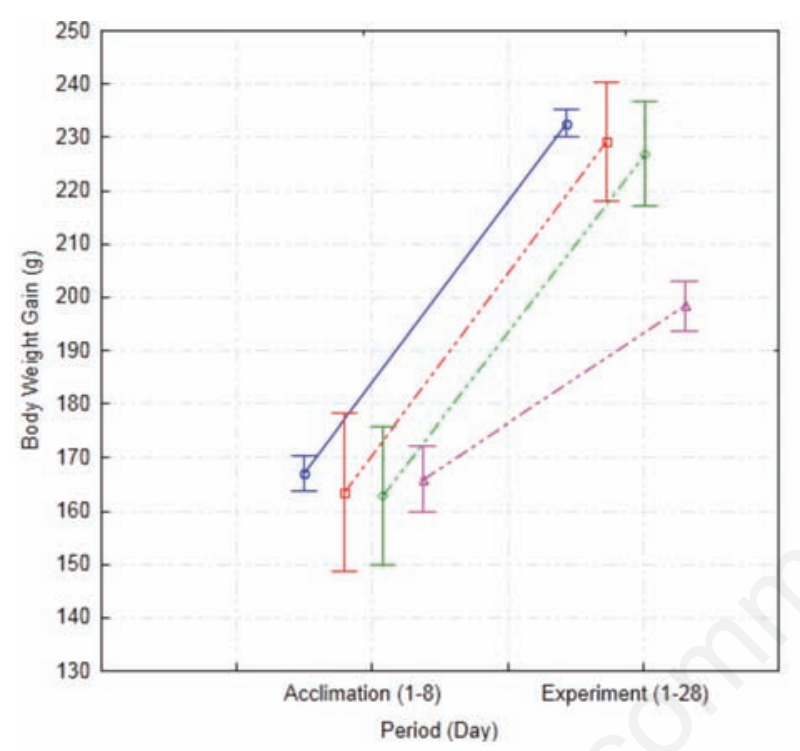

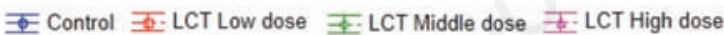

Figure 2. Effect of lambda-cyhalothrin (LCT) on body weight of rats, throughout the acclimation (1-8 days) and experimental (128 days) periods.

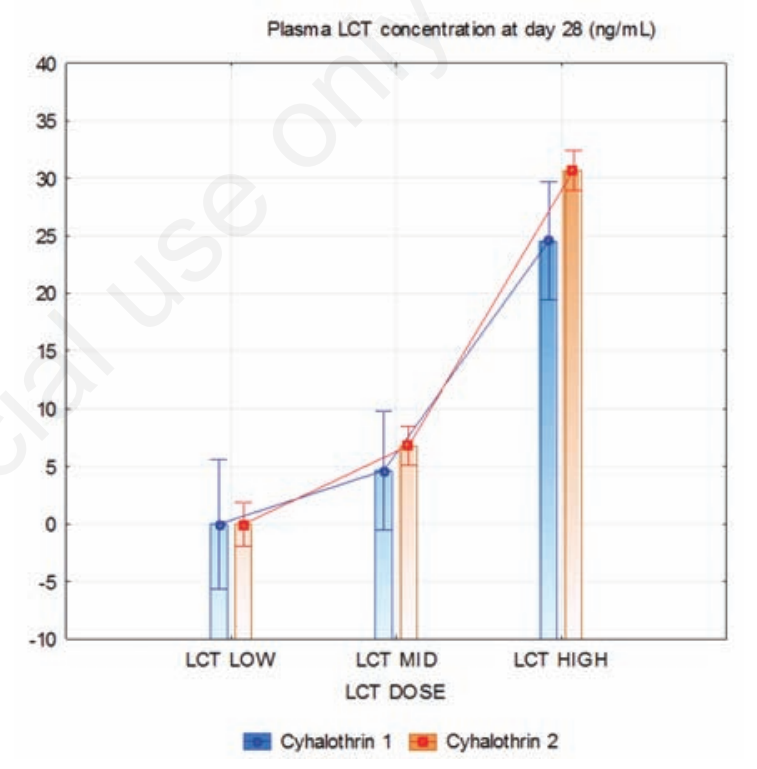

Figure 3. Plasma lambda-cyhalothrin (LCT) cyhalothrin (1) and cyhalothrin (2) concentrations (ng/g) obtained at 28 days after administration of three doses of LCT $(20.4,30.6$ and $61.2 \mathrm{mg} / \mathrm{kg}$ b.w.) daily for 28 days to male rats. Mean $( \pm S D)(n=7)$.

Table 2. Effects of lambda-cyhalothrin on biochemical parameters of blood chemistry in rat.

\begin{tabular}{|c|c|c|c|c|c|}
\hline \multirow[t]{2}{*}{ Parameters } & \multirow[t]{2}{*}{ Days of treatment } & \multicolumn{4}{|c|}{ Groups } \\
\hline & & Control $0 \mathrm{mg} / \mathrm{kg}$ & Low LCT $20.4 \mathrm{mg} / \mathrm{kg}$ & Mid LCT $30.6 \mathrm{mg} / \mathrm{kg}$ & High LCT $61.2 \mathrm{mg} / \mathrm{kg}$ \\
\hline \multirow[t]{2}{*}{ GLUC (g/dL) } & 14 & $1.01 \pm 0.25$ & $1.04 \pm 0.34$ & $1.69 \pm 0.27 *$ & $1.58 \pm 0.16^{*}$ \\
\hline & 28 & $1.02 \pm 0.16$ & $1.06 \pm 0.38$ & $1.89 \pm 0.49 *$ & $1.61 \pm 0.18^{*}$ \\
\hline \multirow[t]{2}{*}{ ALAT (U/L) } & 14 & $44.5 \pm 5.5$ & $42.25 \pm 5.23$ & $43 \pm 5.20$ & $46.25 \pm 5.8^{*}$ \\
\hline & 28 & $45.75 \pm 1.32$ & $39.47 \pm 5.71^{*}$ & $44.83 \pm 1.34$ & $47.80 \pm 1.24^{*}$ \\
\hline \multirow[t]{2}{*}{ ASAT (U/L) } & 14 & $101.5 \pm 8.9$ & $102.01 \pm 5.7$ & $120.3 \pm 8.32^{*}$ & $182.50 \pm 7.40^{*}$ \\
\hline & 28 & $98.6 \pm 13.4$ & $113 \pm 8.9^{*}$ & $142 \pm 7.6^{*}$ & $191 \pm 12.3^{*}$ \\
\hline \multirow[t]{2}{*}{ CREA (mg/dL) } & 14 & $0.66 \pm 0.17$ & $0.66 \pm 0.18$ & $0.89 \pm 0.07^{*}$ & $0.97 \pm 0.24^{*}$ \\
\hline & 28 & $0.65 \pm 0.01$ & $0.62 \pm 0.21$ & $0.75 \pm 0.008 *$ & $0.96 \pm 0.06 *$ \\
\hline \multirow[t]{2}{*}{ UREA (mg/dL) } & 14 & $62.76 \pm 6.03$ & $65.82 \pm 8.45$ & $72.56 \pm 7.86^{*}$ & $75.86 \pm 6.23 *$ \\
\hline & 28 & $64.84 \pm 9.65$ & $66.12 \pm 7.71$ & $97.49 \pm 8.65^{*}$ & $131.68 \pm 9.63^{*}$ \\
\hline \multirow[t]{2}{*}{ Uric acid (mg/dL) } & 14 & $3.2 \pm 2.41$ & $7.37 \pm 1.79 *$ & $5.23 \pm 1.15^{*}$ & $4.45 \pm 2.30^{*}$ \\
\hline & 28 & $2.78 \pm 1.51$ & $2.90 \pm 0.34$ & $2.33 \pm 1.23^{*}$ & $2.24 \pm 0.70 *$ \\
\hline
\end{tabular}

LCT, lambda-cyhalothrin; GLUC, glucose, uric acid; ALAT, alanine aminotransferase; ASAT, aspartate aminotransferase; CREA, plasma creatinine; UREA, blood urea. Values are mean \pm SD ( $\mathrm{n}=7$ for each group). $* \mathrm{P}<0.05$, significantly different from corresponding control values. 
orally to rats may be described as follows.

Body weight gain was significantly $(\mathrm{P}<0.05)$ lower in the $61.2 \mathrm{mg} / \mathrm{kg}$ LCT group than the groups treated with 30.6 and $20.4 \mathrm{mg} / \mathrm{kg}$ or the control group. The study shows that weight gain regressed according to time and dose toxicity. However, lower mean food consumption was noted in the 30.6 and $61.2 \mathrm{mg} / \mathrm{kg}$ LCT groups. This may have been due to the toxic effect causing decreased intake and absorption of nutrients by the gastrointestinal tract and altered efficiency of food conversion as described by Ball and Chhabra. ${ }^{28}$ These results are in agreement with the findings of Yousef, ${ }^{20}$ who reported that treatment with lambda cyhalothrin reduced food intake and body weight in male rabbits. Different pyrethroids have been found to cause body weight change following exposure of rats to this important group of pesticides.,6,29 There was no difference in absolute or relative adrenal weight, but a decrease in the absolute weight of the kidney at low and middle doses and an increase in its relative weight at high dose were observed compared to the control group at the end of the dosing period.

Increases in plasma creatinine, urea and uric acid levels, as observed in 30.6 and 61.2 $\mathrm{mg} / \mathrm{kg}$ LCT-treated rats, are considered as significant markers of renal dysfunction. ${ }^{30,31}$ The study indicates dose- and time-dependent increase in kidney damage and is thus is in agreement with the findings of other studies. ${ }^{19,21}$ Histopathological changes in the kidney were also closely correlated with increased blood urea concentration in rats treated with LCT. The kidneys of treated rats showed a narrowed appearance of Bowman's space, degeneration of tubular epithelial lining, widened lumen and tissue congestions. These results are in agreement with those of Fetoui et al., ${ }^{19}$ who observed similar lesions in the kidneys of rats treated with LCT. In addition to the increase in kidney parameters, our tests revealed that glucose, ALAT and ASAT, two excellent markers of liver damage, increased significantly for low and middle or high doses. Results in the literature also confirm our results. For instance, Fetoui et al. ${ }^{32}$ observed enhanced activities of transaminases (ASAT and ALAT) and revealed hepatic damage in rats treated by lambda cyhalothrin. Insecticides are capable of inducing apoptosis by multifunctional pathways, e.g. when cells are exposed to oxidative stress, they often die by apoptosis or necrosis. Deltamethrin, a pyrethroid pesticide, has been reported to induce apoptosis ${ }^{10}$ and lambda-cyhalothrin has been shown to cause oxidative stress in mammals. ${ }^{19,33}$ The oxidative damage induced by pyrethroids is attributed to their lipophilic nature, which enables their easy penetration and accumulation in cell membranes, leading to disturbance or destruction of the membrane. Damage to the mem-
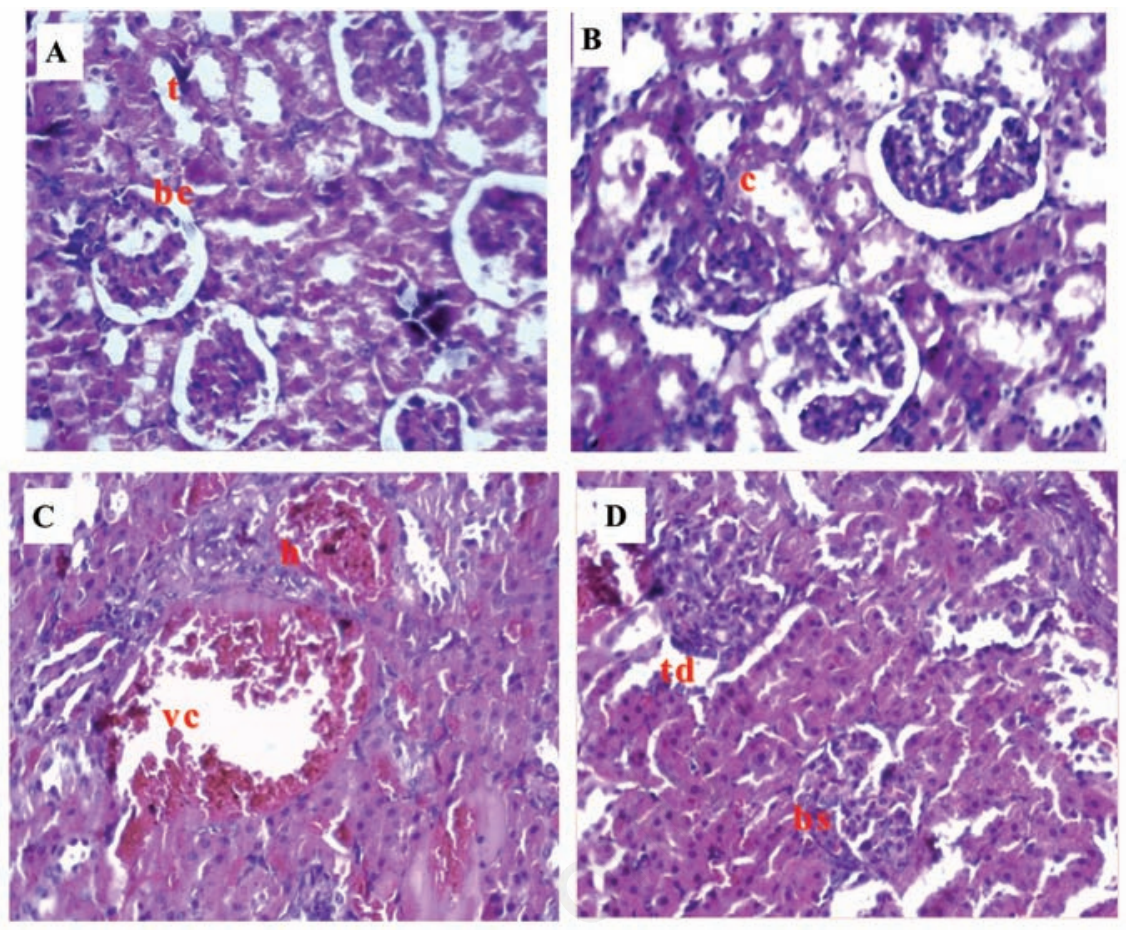

Figure 4. Hematoxylin and eosin staining after administration of lambda-cyhalothrin (LCT) for 28 days (original magnification $400 \times$ ). A) Group treated with $0 \mathrm{mg} / \mathrm{kg}$ of LCT, showing normal architecture, renal corpuscles with Bowman's capsules (bc), and normal proximal and distal convoluted tubules $(\mathrm{t}) ; \mathrm{B})$ group treated with $20.4 \mathrm{mg} / \mathrm{kg}$ of LCT, showing a normal cortex; C) group treated with $30.6 \mathrm{mg} / \mathrm{kg}$ of LCT, showing vascular congestion (vc) and hemorrhage (h); D) group treated with $61.2 \mathrm{mg} / \mathrm{kg}$ of LCT showing narrowed Bowman's space (bs) and extensive tubular dilatation (tb). Changes increased in a dose-dependent manner.
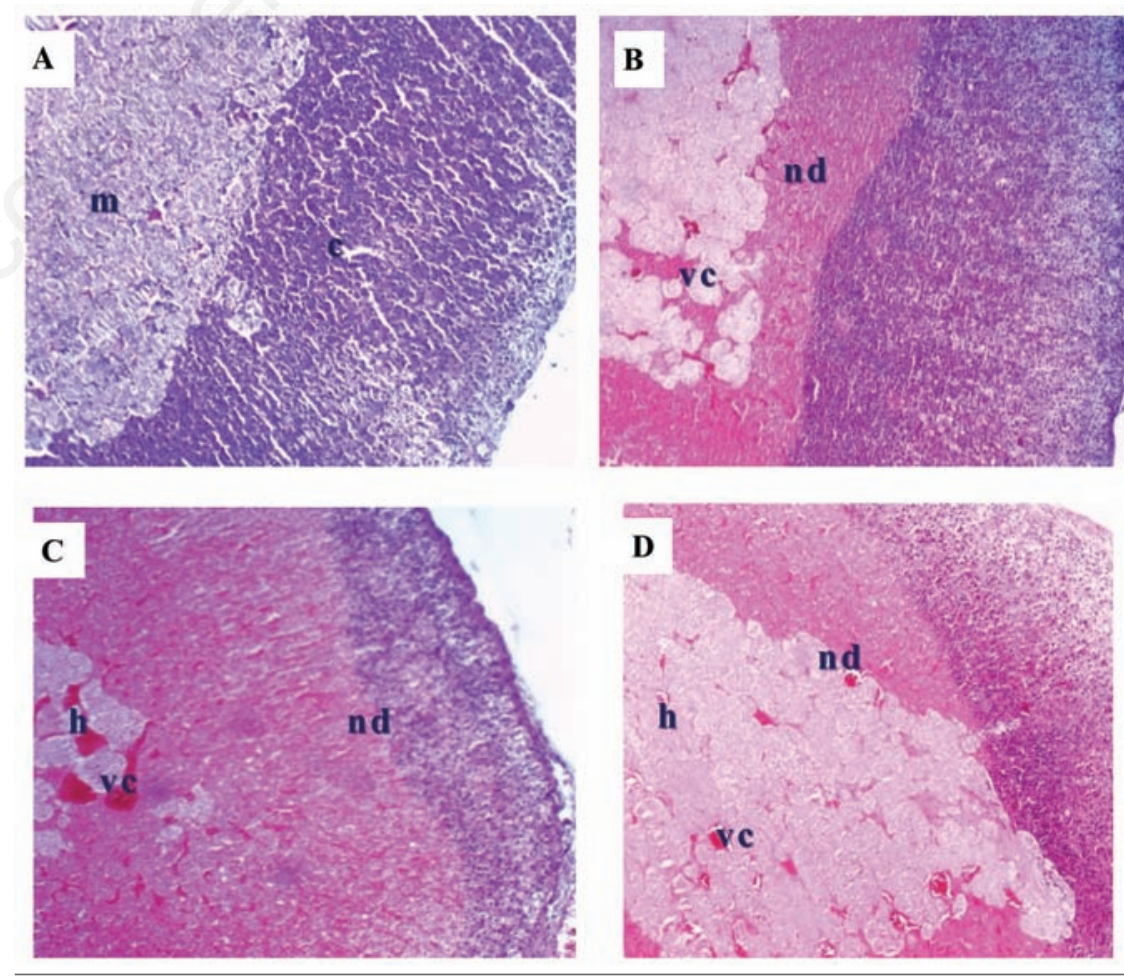

Figure 5. Photomicrographs of adrenal glands from control rats (A), showing normal cortex $(\mathrm{c})$ and medulla $(\mathrm{m})$, and from rats given lambda-cyhalothrin at the dose of 20.4 $\mathrm{mg} / \mathrm{kg}$ (B), $30.6 \mathrm{mg} / \mathrm{kg}$ (C) or (D) $61.2 \mathrm{mg} / \mathrm{kg}$ (D), showing extensive necrotic degeneration (nd) of the adrenal cortex, vascular congestion (vc) and areas of hemorrhage (h) (hematoxylin and eosin 200x). 
brane is thus a menace to the viability of the cells. $^{11,34}$ In the present study, the adrenal glands were the most vulnerable organs and necrotic cortices were apparent in all LCTtreated groups.

In this study, a sensitive gas chromatographic method was developed for the determination of lambda-cyhalothrin insecticide residues in plasma. In the rat plasma samples after 28 days, LCT $1 \mathrm{R}, \mathrm{cis}, \alpha \mathrm{S}$ cyhalothrin (1) and $1 \mathrm{~S}, \mathrm{cis}, \alpha \mathrm{R}$, cyhalothrin (2) were clearly detected. In GC-MS 2 , two peaks were observed in the chromatograms for lambda cyhalothrin due to the separation of its diastereoisomers. However, a handicap in analyzing LCT is that the concentration of each isomer in the standard mixture should be known but, generally, the technical standard mixtures of pyrethroids only indicate the sum of the concentrations of the individual isomers for each pyrethroid..$^{35}$ Residues of lambda-cyhalothrin have been reported in vegetables and fruits ${ }^{13,36,37}$ and other biological samples. ${ }^{38}$

In conclusion, according to the literature and our findings, exposure to lambda cyhalothrin, especially at higher doses, may produce toxic effects on the adrenal and kidney tissues. More investigations with lambda cyhalothrin need to be performed to investigate the impact of this xenobiotic in human diseases.

\section{References}

1. Burrows HD, Canle ML, Santaballa JA, Steenken S. Reaction pathways and mechanisms of photodegradation of pesticides. J Photochem Photobiol 2002;B67:71-108.

2. Reffstrup TK. Combined actions of pesticides in food (Fødevare rapport no. 2002:19). Søborg: Danish Veterinary and Food Administration; 2002.

3. Soderlund DM, Clark JM, Sheets PL, Mullin LS, Piccirillo VJ, Sargent D, et al. Mechanisms of pyrethroid neurotoxicity: implications for cumalative risk assessment. Toxicology 2002;171:3-59.

4. Casida JE. Pyrethrum flowers and pyrethroid insecticides. Environ Health Perspect 1980;34:189-202.

5. Righi DA, Palermo-Neto J. Effects of type II pyrethroids cyhalothrin on peritoneal macrophage activity in rats. Toxicology 2005;212:98-106.

6. Prasanthi K, Muralidhara PS, Rajini K. Fenvalerate-induced oxidative damage in rat tissues and its attenuation by dietary sesame oil. Food Chem Toxicol 2005;43: 299-306.

7. Naumann K. Synthetic pyrethroid insecticides: structures and properties. Chemistry of plant protection. Vol. 4.
Springer Verlag: Berlin; 1990

8. Breckenridge C, Holden L, Sturgess N, Weiner M, Sheets L, Sargent D, et al. Evidence for a separate mechanism of toxicity for the Type I and the Type II pyrethroid insecticides. NeuroToxicology 2009;30S:S17-31.

9. Burr SA, Ray DE. Structure-activity and interaction effects of 14 different pyrethroids on voltage-gated chloride ion channels. Toxicol Sci 2005;77:341-6.

10. Hossain MM, Richardson JR. Mechanism of pyrethroid pesticide-induced apoptosis: role of calpain and the ER stress pathway. Toxicol Sci 2011;122:512-25.

11. Ali ZY. Neurotoxic effect of lambdacyhalothrin, a synthetic pyrethroid pesticide: involvement of oxidative stress and protective role of antioxidant mixture. N Y Sci J 2012;9:93-103.

12. Cheng JH, Liu M, Yu Y, Wang XP, Zhang HQ, Ding L. Determination of pyrethroids in porcine tissues by matrix solid-phase dispersion extraction and high-performance liquid chromatography. Meat Sci 2009;82:407-12.

13. Turrillas FAE, Pastor A, Guardia MD. Determination of pyrethroid insecticide residues in vegetable oils by using combined solid-phases extraction and tandem mass spectrometry detection. Anal Chim Acta 2005;553:50-7.

14. De-Micco A, Cooper KR, Richardson JR, White LA. Developmental neurotoxicity of pyrethroid insecticides in zebrafish embryos. Toxicol Sci 2010;113:177-86.

15. Colombo R, Ferreira TCR, Alves SA, Carneiro RL, Lanza MRV. Application of the response surface and desirability design to the Lambda-cyhalothrin degradation using photo-Fenton reaction. J Environ Manage 2013;118:32-9.

16. Kumar A, Rai DK, Sharma B, Pandey RS. $\lambda$-cyhalothrin and cypermethrin induced in vivo alterations in the activity of acetylcholinesterase in a freshwater fish, Channa punctatus (Bloch). Pestic Bio chem Phys 2009;93:96-9.

17. Liu S, Pleil JD. Human blood and environmental media screening method for pesticides and polychlorinated biphenyl compounds using liquid extraction and gas chromatography-mass spectrometry analysis. J. Chromatogr 2002;769:155-67.

18. FAO/WHO evaluation report based on submission of data from Bharat Rasayan Limited (TC). In: Food and Agriculture Organization, ed. FAO specifications and evaluations for agricultural pesticides Lambda-cyhalothrin. Rome: FA0; 2012. pp 15-23. Available from: http://www.fao.org/ fileadmin/templates/agphome/documents/Pests_Pesticides/Specs/lambda13.p df
19. Fetoui H, Makni M, Garoui Zeghal EMN. Toxic effects of lambda-cyhalothrin, a synthetic pyrethroids pesticide, on the rat kidney: involvement of oxidative stress and protective role of ascorbic acid. Exp Toxicol Pathol 2010;62:593-9.

20. Yousef IY, Vitamin E. Modulates reproductive toxicity of pyrethroid lambdacyhalothrin in male rabbits. Food Chem Toxicol 2010;48:1152-9.

21. Velmurugan B, Selvanayagama M, Cengiz EI, Unlu E. Histopathology of lambdacyhalothrin on tissues (gill, kidney, liver and intestine) of Cirrhinus mrigala. Environ Toxicol Pharmacol 2007;24:286-329.

22. Muller J. Aldosterone the minority hormone of the adrenal cortex. Steroids 1995;60:29.

23. Organization for Economic Cooperation and Development (OECD). Test Guideline for testing of chemicals, Section 4:

Health Effects, OECD. Guideline 407, Repeated Dose 28-Day Oral Toxicity Study in Rodents 2003. Paris: OECD; 2003.

24. Çelik A, Mazmancia B, Çamlica Y, Skin AA, Çömelekoglu Ü. Cytogenetic effects of lambda-cyhalothrin on Wistar rat bone marrow. Mutat Res 2003;539:91-7.

25. Ayla MB, Çamlica Y, Çömelekoglu Ü, Skin AA. Evaluation of cytogenetic effects of lambda-cyhalothrin on Wistar rat bone marrow by gavage administration. Ecotoxicol Environ Safety 2005;61:128-33.

26. El-Demerdash FM. Lambda-cyhalothrininduced changes in oxidative stress biomarkers in rabbit erythrocytes and alleviation effect of some antioxidants. Toxicol In Vitro 2007;21:392-7.

27. Pratera MR, Gogal JRAR, Blaylockb BL, Longstrethc J, Holladaya SD. Single-dose topical exposure to the pyrethroid insecticide, permethrin in $\mathrm{C} 57 \mathrm{BL} / 6 \mathrm{~N}$ mice: effects on thymus and spleen. Food Chem Toxicol 2002;40:1863-73.

28. Ball LM, Chhabra RS. Intestinal absorption of nutrients in rats treated with $2,3,7,8$ tetrachlorodi benz-p-dioxin (TCDD). J Toxicol Environ Health 1981;8:629-36.

29. Kilian Delport ER, Bornman MS, De Jager C. Simultaneous exposure to low concentrations of dichlorodiphenyltrichloroethane, deltamethrin, nonylphenol and phytoestrogens has negative effects on the reproductive parameters in male SpragueDawley rats. Andrologia 2007;39:128-35.

30. Coles EH. Veterinary clinical pathology. Philadelphia, PA: W.B. Saunders; 1986.

31. Almdal TP, Vilstrup H. Strict insulin treatment normalizes the organic nitrogen contents and the capacity of urea-N synthesis in experimental diabetes in rats. Diabetologica 1988;31:114-8.

32. Fetoui H, Garoui EM, Zegha IE. Lambdacyhalothrin-induced biochemical and 
histopathological changes in the liver of rats: ameliorative effect of ascorbic acid. Exp Toxicol Pathol 2009;61:189-96.

33. Yousef MI, El-Demerdash FM, Kamel KI, Al-Salhen KS. Changes in some hematological and biochemical indices of rabbits induced by isoflavones and cypermethrin. Toxicol 2003;189:223-34.

34. Piner P, Üner N. Oxidative and apoptotic effects of lambda-cyhalothrin mod-ulated by piperonyl butoxide in the liver of
Oreochromis niloticus. Environ Toxicol Pharmacol 2012;33:414-20.

35. Li M, Wang J, Lu ZD, Wei M, Yang L, Kong HM. NMR-based metabolomics approach to study the toxicity of lambda-cyhalothrin to goldfish (Carassius auratus) Aquat Toxicol 2014;146:82-92.

36. Wolansky MJ, Gennings C, Crofton KM. Relative potencies for acute effects of pyrethroids on motor function in rats. Toxicol Sci 2006;89:271-7.
37. Lofty AEAA, Abd El-Aleem, HH. Monir. Determination of insecticides malathion and lambda-cyhalothrin residues in zucchini by gas chromatography. Bulletin of Faculty of Pharmacy, Cairo University 2013;51:255-60.

38. Feo ML, Eljarrat E, Barcelo D. Determination of pyrethroid insecticides in environmental samples. Trends Anal Chem 2010;29:692-705. 